\title{
Identification of potential sources of Staphylococcus aureus in herds with mastitis problems
}

\author{
A. Capurro, ${ }^{*} \dagger$ A. Aspán, ${ }^{*}$ H. Ericsson Unnerstad, ${ }^{*}$ K. Persson Waller, ${ }^{*}{ }^{1}$ and K. Artursson ${ }^{*}$ \\ ${ }^{*}$ National Veterinary Institute, SE-75189 Uppsala, Sweden \\ †Swedish University of Agricultural Science, SE-75007 Uppsala, Sweden
}

\begin{abstract}
Staphylococcus aureus is a common udder pathogen of dairy cows that often causes herd problems. Various mastitis control programs have been used to combat the problem but have not always been efficient in preventing new Staph. aureus infections, indicating the presence of possible sources of infection other than those traditionally considered. Therefore, the aim of the study was to identify potential sources of infection relevant for Staph. aureus mastitis within 5 dairy herds with udder health problems caused by Staph. aureus. Samples were collected from milk of lactating cows, from body sites, and from the environment of lactating cows, dry cows, late pregnant heifers, young heifers 4 to $12 \mathrm{mo}$ old, and heifer calves 0 to 3 mo old. Isolates of Staph. aureus were identified and compared using pulsed-field gel electrophoresis. Four to 7 unique Staph. aureus pulsotypes were found within each herd, with one strain predominating in milk in each herd. The milk pulsotypes were also frequently isolated in body samples, especially on hock skin, and in the immediate environment of lactating cows, and were sometimes found in other animal groups, especially in dry cows and heifer calves 0 to $3 \mathrm{mo}$ old. The prevalence of Staph. aureus in milk and other types of samples varied markedly between herds. Staphylococcus aureus isolates with genotypes indistinguishable from those found in milk also dominated in extra-mammary sites within the dairy herds studied, and hock skin was identified as an important reservoir of Staph. aureus. The results contribute new knowledge necessary to improve strategies for udder health control in herds.
\end{abstract}

Key words: bovine mastitis, Staphylococcus aureus, pulsed-field gel electrophoresis, extra-mammary sites

\section{INTRODUCTION}

Staphylococcus aureus is a common bovine udder pathogen in many countries (Gianneechini et al., 2002;

Received June 9, 2009.

Accepted October 5, 2009.

${ }^{1}$ Corresponding author: Karin.Persson-Waller@sva.se
Pitkala et al., 2004; Ferguson et al., 2007; Olde Riekerink et al., 2008). In Sweden, Staph. aureus is the most common udder pathogen in both clinical and subclinical mastitis of dairy cows. In a recent nationwide survey on distribution of udder pathogens in clinical mastitis, Staph. aureus accounted for $21.3 \%$ of the diagnoses obtained (Ericsson Unnerstad et al., 2009).

Staphylococcus aureus is generally considered to be a contagious udder pathogen, which mainly spreads within and between cows at milking; the udder is the main source of infection. Therefore, control measures are primarily aimed at improving milking hygiene and milking routines such as milking order and teat dipping. Dry cow therapy and culling of infected animals are other measures taken in control programs. However, such control measures are not always efficient in preventing new Staph. aureus infections (Sommerhauser et al., 2003), indicating the complexity of the problem and the possibility of other sources of infection.

The probability of udder infection increases if the host has direct contact with the reservoirs of pathogens or indirect contact via fomites (reviewed by Zecconi et al., 2006). Reservoirs and fomites of pathogens such as Staph. aureus can be traced by phenotyping and genotyping of the bacteria. Several studies investigating potential reservoirs and fomites of Staph. aureus in dairy farms have been performed (Spencer and Lasmanis, 1952; Davidson, 1961; Fox et al., 1991; Matos et al., 1991; Roberson et al., 1994b, 1998; Larsen et al., 2000; Middleton et al., 2002; Zadoks et al., 2002; Jorgensen et al., 2005; Haveri et al., 2008; Piccinini et al., 2009). Most of these studies investigated extra-mammary sites associated with spread of infection at milking such as teat skin of lactating cows, milking liners, and milkers' hands and nostrils. Only a few studies investigated the presence of Staph. aureus on other body sites of the lactating cow, in other age groups of cattle, or in the environment of the animals (Matos et al., 1991; Roberson et al., 1994b, 1998; Jorgensen et al., 2005). None of the studies investigated hock lesions as a potential reservoir of Staph. aureus. Hock lesions may be a common finding in certain housing systems (e.g., Weary and Taszkun, 2000; Fulwider et al., 2007), and an association between hock 
Table 1. Descriptive data for the milk-recording year September 2006 to August 2007 for 5 tie-stall herds with udder health problems caused by Staphylococcus aureus, and for 5,465 herds (national) enrolled in the Swedish milk recording system

\begin{tabular}{|c|c|c|c|c|c|c|}
\hline \multirow[b]{2}{*}{ Variable } & \multicolumn{5}{|c|}{ Herd $^{1}$} & \multirow[b]{2}{*}{ Nationa } \\
\hline & I & II & III & IV & $\mathrm{V}$ & \\
\hline Average yield, kg/cow-year & 8,990 & 9,508 & 10,150 & 8,415 & 7,868 & 9,410 \\
\hline Proportion of cows treated by a veterinarian for mastitis, $\%$ & 47 & 34 & 8 & 32 & 27 & 16 \\
\hline Proportion of cows with UDS $^{2} 6-9, \%$ & 48 & 37 & 33 & 50 & 49 & 13 \\
\hline
\end{tabular}

${ }^{1}$ Data are given for the whole herd. Herd I had one barn with tie-stalls and one with free stalls; only the cows in the tie-stall barn were included in the study. In herd III, a convenience sample of 50 cows was included in the study.

${ }^{2}$ Animals with a UDS (udder disease score) 6-9 have a probability of 69 to $99 \%$ that one or more udder quarters are infected. The score corresponds approximately to having had a SCC of $>300,000$ cells $/ \mathrm{mL}$ on 3 consecutive monthly milk recordings.

lesions and high milk SCC has been reported (Fulwider et al., 2007). Moreover, in many studies identification was made at the species level, not at the strain level. Identification at the strain level is essential to make a correct identification of reservoirs and fomites because several Staph. aureus strains may occur in the same herd (e.g., Sommerhauser et al., 2003). Among studies attempting to identify Staph. aureus strains associated with intramammary infections in extra-mammary sites, Middleton et al. (2002), Zadoks et al. (2002), Jorgensen et al. (2005), Haveri et al. (2008), and Piccinini et al. (2009) used pulsed-field gel electrophoresis (PFGE), which today is considered the gold standard for typing of bovine Staph. aureus because of its excellent typeability, reproducibility, discriminatory power, and easy interpretation (Bannerman et al., 1995; Zadoks et al., 2002).

The main aim of the study was to identify potential sources of infection relevant for Staph. aureus mastitis within dairy herds with udder health problems caused by Staph. aureus and thus to identify sources that had previously been neglected in attempts to control the disease. To identify relevant Staph. aureus strains, isolates from milk, body sites of animals of different age groups, and the environment of these animals were identified and compared using PFGE. Another aim was to investigate associations between hock skin condition and presence of Staph. aureus strains of relevance for udder health.

\section{MATERIALS AND METHODS}

\section{Herd Information}

Five dairy herds (herds I to V) meeting the inclusion criteria (tie stalls, enrolled in the cow control scheme, and willingness to cooperate in the project) and having a herd problem caused by Staph. aureus mastitis (as judged by the herd veterinarian and herd statistics) were visited and sampled between December 2006 and
March 2007. Herd size ranged from 32 to 90 cows per year. All herds had tie-stalls for lactating cows, but herd I had another barn with free-stalls. Descriptive herd information is summarized in Table 1. In all herds, milking was performed twice per day.

\section{Sampling}

Each herd was visited 2 or 3 times within a period of 1 to 2 wk. The number of visits to each herd depended on the number of animals to be sampled. All dry cows, late pregnant ( $<3$ mo before estimated calving) heifers, young heifers ( 4 to 12 mo old) and heifer calves ( 0 to 3 mo old) present in the farms at the time of sampling were included in the study. All lactating cows in herds II, IV, and V were also included. In herd I, only cows present in the tie-stall barn were included. In herd III, a convenience sample of 50 lactating cows was selected. The numbers of animals and samples taken in each group are given in Tables 2 to 6 . Milk samples were taken from all lactating cows included in the study, and body samples were taken from all animals in the different groups. In addition, the condition of the hock skin of lactating cows was scored as intact, with hair loss, or with hair loss and wounds. Samples from the animals' immediate environment in each group were also taken. In addition, body samples of all dogs, cats, and humans present or working in the barn at the time of the visits were also included. Moreover, samples were taken from general areas such as milking equipment, tools, flies, air, and stores of feed and bedding.

In each herd, the farmer was interviewed about management routines and housing using a questionnaire. Sampling was performed according to the same schedule in each herd. At the first visit, quarter milk samples and teat skin samples were taken from lactating cows. Flies and air samples were also collected. At the subsequent visits, body and environment samples were taken from lactating cows, dry cows, late pregnant heifers, young heifers, heifer calves, dogs, cats, and humans. At the 
same visit, samples were also taken from general areas as specified below (called other samples). Disposable gloves were worn at all samplings and were changed between each animal, human, or sampling area.

Quarter Milk Samples. Udder quarter milk samples (QMS) were collected aseptically from lactating quarters of lactating cows at least $1 \mathrm{~h}$ after morning milking. Three strips of milk were discarded before sampling. The sampling was performed by trained personnel using recommended methods (Hogan et al., 1999).

Body Samples. In all age groups, body samples were taken from the following sites; teat skin, groin, vagina, nares/muzzle, hock skin, and skin wounds (when present). In heifer calves, the umbilical area was also sampled.

Teat/udder skin, groin, hock skin, and skin wounds were sampled on only one side of each animal. When the animals were housed in tie-stalls (lactating and dry cows, late pregnant heifers), the animals were paired and sampling was performed between the animals of each pair, meaning that one animal was sampled on the left side and the other on the right side of the body. Animals of other age groups were housed in loose housing systems and were sampled from the side easiest to access. All samples were taken using sterile cotton swabs. Before all samplings except vagina and nares/ muzzle, the swab was moistened in sterile saline.

The teat skin was sampled by gently rolling the swab downward from the middle of the side of the teat over the teat apex and up the other side of the teat. One swab was used for each teat, but the 2 swabs formed one sample. Teat skin samples of lactating cows were taken immediately before milk sampling. If visible dirt was present, a dry sterile cotton compress was used to clean the skin before sampling. In young heifers and heifer calves it was not possible to sample only the teat skin because of the small size of the teats so the sample was taken from both teat and udder skin. The groin was sampled by rotating a swab on the skin between the hind leg and the udder. The vagina was sampled, after parting the lips of the vulva, by gently inserting a swab and rolling it on the mucosa of the vestibular area. The nares/muzzle area was sampled by rolling a swab on the muzzle and along the mucosa just inside one of the nares. The hock skin was sampled by rolling a swab over the area. Skin wounds and the umbilical region were also sampled by rolling a swab over the area.

The numbers of skin wounds sampled were 22, 11, 14,5 , and 10 in herds I to $\mathrm{V}$, respectively. The numbers of skin wounds sampled in each group of animals were $34,6,2,2$, and 18 , in lactating cows, dry cows, late pregnant heifers, young heifers, and heifer calves, respectively.

Samples from the Animals' Immediate Environment. Samples were taken from the immediate environment of each group of animals. When animals were in tie-stalls (lactating cows, dry cows, late pregnant heifers), the cubicles of 2 animals were, in most cases, handled as one sampling unit. When animals were housed loose in single or group pens, one pen was handled as one sampling unit.

Composite samples were taken from stanchion bars and cubicle surfaces, water cups, and under the rubber mats (when present) by swabbing the surface areas with dry swabs. In each type of environment, 2 swabs were used and combined into one sample. Samples of feed from the feed bunks and bedding were taken by collecting 4 handfuls of each material from different areas of the feed bunks and cubicles/pens into sterile plastic bags suitable for frozen storage.

Other Samples (Humans, Dogs, Cats, General Areas). From each human present in the barn, samples were taken from hands, nostrils, and the soles of their boots. A sterile cotton swab moistened in sterile saline was used to sample the hands by rolling the swab over the palms and between the fingers of both hands. A dry swab was gently inserted into each nostril and rolled along the mucosa. The soles of the rubber boots were sampled by rolling a moistened swab over the sole of each boot.

Dogs or cats present in the barn were also sampled. Swab samples were taken from nares/muzzle in the same manner as for bovines. A swab sample was also taken under the paws of the animal. The animals were inspected for wounds, which were sampled using swabs if observed.

Milking equipment (strip cups, teat cups, and udder cleaning cloths), general tools (brushes, hay forks), and buckets for feeding liquids to young calves were sampled by swabbing its surface using a moistened swab. Fresh bedding and feed samples were collected from the storage areas. For each type of material, 10 handfuls were taken from various parts of the storage area. The material was mixed in a sterile plastic bag suitable for freezing. From the barn of the lactating cows, fly and air samples were taken at the same occasion. For each fly sample, 5 to 10 flies were collected using a sterile net and the flies were placed into empty sterile plastic bags. The air sample was taken in the middle of the barn using an air pump (Gilair-3, Sensidyne LP, Clearwater, FL). For $1 \mathrm{~h}$, air was pumped through a polycarbonate filter (pore size of $0.4 \mu \mathrm{m}$ ) at a flow rate of $1.5 \mathrm{~L} / \mathrm{min}$. The filter was situated inside a filter house, which was removed from the air pump after sampling. 
A total of 257 other samples were taken $(45,49,56$, 41 , and 66 from herds I to V, respectively). In each herd the following numbers of samples were taken, 6 to 10 from humans, 2 to 15 from dogs/cats, 4 to 11 from milking teat cups, 1 to 5 from teat dipping cups, 1 to 3 from strip cups, 1 to 3 from udder cleaning clothes, 7 to 12 from tools (e.g., brushes/hay forks), 3 to 10 from buckets for feeding young calves, 3 to 7 from storage areas of feed/bedding, 1 to 4 from flies, and 2 to 3 from air.

Sample Storage and Transportation. All swab samples were placed in test tubes containing $3 \mathrm{~mL}$ of sterile liquid Vogel-Johnson (VJ) medium (National Veterinary Institute, Uppsala, Sweden) immediately after sampling (Fox et al., 1992). All types of samples were stored chilled in cooling boxes $\left(+5^{\circ} \mathrm{C}\right)$ while at the farm and during transportation to the laboratory. Quarter milk samples were processed on the day of sampling. Swab samples stored in VJ were refrigerated $\left(+5^{\circ} \mathrm{C}\right)$ overnight. Bags with flies and air filter houses were frozen at $-20^{\circ} \mathrm{C}$, and flies and filters were processed within $48 \mathrm{~h}$. Feed and bedding samples were frozen at $-20^{\circ} \mathrm{C}$ and further analyzed within 3 mo.

\section{Bacteriology}

After arrival at the laboratory, QMS were incubated at $37^{\circ} \mathrm{C}$ for 16 to $18 \mathrm{~h}$. Then, $10 \mu \mathrm{L}$ of milk was cultured on $5 \%$ bovine blood agar plates with $0.05 \%$ esculin (Oxoid Ltd., Basingstoke, UK). The agar plates were incubated at $37^{\circ} \mathrm{C}$ for 16 to $24 \mathrm{~h}$. Body and environment samples in VJ medium were adjusted to room temperature for 1 to $2 \mathrm{~h}$ followed by incubation at $37^{\circ} \mathrm{C}$ for $4 \mathrm{~h}$ (Fox et al., 1992). Then, $10 \mu \mathrm{L}$ of sample was cultured on $5 \%$ bovine blood agar with esculin and on modified Baird-Parker medium (MBP; Devriese, 1981). The blood agar and MBP plates were incubated at $37^{\circ} \mathrm{C}$ for 16 to $24 \mathrm{~h}$ and $48 \mathrm{~h}$, respectively.

Bedding and feed samples were thawed in room temperature and processed by mixing $90 \mathrm{~mL}$ of VJ medium with $10 \mathrm{~g}$ of sample material in a stomacher bag, which was treated for $120 \mathrm{~s}$ in a Seward Stomacher 400 Laboratory Blender (Seward Ltd., Worthing, West Sussex, UK). Thereafter, the bags were incubated at $37^{\circ} \mathrm{C}$ for 4 $\mathrm{h}$, and $10 \mu \mathrm{L}$ of the sample mix was inoculated on $5 \%$ bovine blood agar with esculin and on MBP agar.

Flies and air filter houses were thawed at room temperature. The flies were placed into sterile test tubes containing $3 \mathrm{~mL}$ of VJ medium. The air filter was removed from the filter house under sterile conditions. The filter was cut into small pieces and placed into a sterile test tube containing $3 \mathrm{~mL}$ of VJ medium. The fly and air filter samples were then processed as described above for body and environment samples.
In all samples, growth of Staph. aureus on blood agar was evaluated in accordance with accredited routines at the laboratory. Staphylococcus aureus was identified by typical colony morphology and the presence of $\alpha \beta$ hemolysis. When only $\alpha$-hemolysis or no hemolysis zones were present, coagulase reaction (coagulase positive), reverse CAMP (Christie, Atkins, Munch-Petersen) reaction (Quinn et al., 1994), and growth in $\mathrm{P}$ agar with acriflavin (Roberson et al., 1992) were evaluated. A sample was classified as positive if at least one colonyforming unit of Staph. aureus was isolated. Growth of Staph. aureus on MBP agar was evaluated according to Devriese (1981) and Matos et al. (1991) with some modifications. From each MBP agar plate, a maximum of 4 cfu with black, dark gray, or shiny brown appearance, with or without clear zones, were cultured on $5 \%$ bovine blood agar with $0.05 \%$ esculin. All Staph. aureus isolates (maximum 1 isolate per sample) were stored at $-70^{\circ} \mathrm{C}$ in trypticase soy broth (Oxoid Ltd.) containing $15 \%$ glycerol until analyzed using PFGE.

After thawing, the Staph. aureus isolates were subcultured (overnight at $37^{\circ} \mathrm{C}$ ) twice on $5 \%$ bovine blood agar with $0.05 \%$ esculin before use in further studies. Then, PFGE was carried out according to the Harmony protocol (www.harmony-microbe.net). Macrorestriction patterns were analyzed by visual inspection. Isolates with identical restriction profiles were assigned the same PFGE pulsotype (PT). Isolates that differed by 1 band or more were considered to be of different PT.

\section{Statistics}

Descriptive statistics of the prevalence of Staph. aureus positive samples and animals in the different animal groups and herds are given in Tables 2 to 6 . Univariable associations between presence of Staph. aureus in milk, presence of Staph. aureus on hock skin, and hock skin condition within all lactating cows were evaluated using hierarchical logistic regression with herd as random factor (Stata Statistical Software, release 9.0, 2005, StataCorp LP, College Station, TX). To investigate differences between herds in findings of Staph. aureus in milk, findings of Staph. aureus on hock skin, and hock skin condition univariable logistic regression models were used with herd as explanatory variable and Staph. aureus in milk, Staph. aureus on hock skin, or hock skin condition as dependent variable in 3 separate models. Univariable logistic regression was also used to investigate associations between presence of Staph. aureus in milk, presence of Staph. aureus on hock skin, and hock skin condition among lactating cows within each herd.

Within-herd associations between finding the same Staph. aureus PT in at least one quarter milk sample, 
Table 2. Lactating cows: Numbers of animals sampled, numbers of quarter milk samples (QMS), body samples (BS), and environment samples (ES) taken, and numbers (\%) of animals, QMS, BS, and ES positive for Staphylococcus aureus (Sa+) in 5 dairy herds (I to V) with Staph. aureus mastitis problems ${ }^{1}$

\begin{tabular}{|c|c|c|c|c|c|c|c|c|c|c|c|c|}
\hline \multirow[b]{2}{*}{ Sample information } & \multicolumn{11}{|c|}{ Herd/PT } & \multirow[b]{2}{*}{ Total } \\
\hline & IA & IB-G & IIA & IIB-F & IIIA & IIIB-E & IVA & IVB-E & $\mathrm{VA}$ & VB-C & VD & \\
\hline Total animals, $\mathrm{n}$ & \multicolumn{2}{|c|}{47} & \multicolumn{2}{|c|}{27} & \multicolumn{2}{|c|}{47} & \multicolumn{2}{|c|}{34} & \multicolumn{3}{|c|}{36} & 191 \\
\hline Total QMS, n & \multicolumn{2}{|c|}{186} & \multicolumn{2}{|c|}{108} & \multicolumn{2}{|c|}{184} & \multicolumn{2}{|c|}{136} & \multicolumn{3}{|c|}{143} & 757 \\
\hline Total BS, n & \multicolumn{2}{|c|}{245} & \multicolumn{2}{|c|}{141} & \multicolumn{2}{|c|}{242} & \multicolumn{2}{|c|}{172} & \multicolumn{3}{|c|}{188} & 988 \\
\hline Animals $\mathrm{Sa}+$ in BS & $26(55)$ & $0(0)$ & $17(63)$ & $2(7)$ & $29(62)$ & $6(13)$ & $0(0)$ & $1(3)$ & $3(8)$ & $0(0)$ & $9(25)$ & $89^{3}(47)$ \\
\hline $\mathrm{BS} \mathrm{Sa+}$ & $34(14)$ & $0(0)$ & $29(21)$ & $2(1)$ & $37(15)$ & $7(3)$ & $0(0)$ & $1(1)$ & $3(2)$ & $0(0)$ & $18(10)$ & $131(13)$ \\
\hline Teat skin & 2 & 0 & 5 & 0 & 2 & 1 & 0 & 0 & 2 & 0 & 7 & 19 \\
\hline Groin & 4 & 0 & 3 & 0 & 2 & 1 & 0 & 0 & 0 & 0 & 3 & 13 \\
\hline Vagina & 2 & 0 & 0 & 1 & 1 & 0 & 0 & 0 & 1 & 0 & 3 & 8 \\
\hline Nares/muzzle & 0 & 0 & 3 & 0 & 4 & 1 & 0 & 1 & 0 & 0 & 0 & 9 \\
\hline Under rubber mats & 1 & 0 & 0 & 0 & 4 & 0 & 0 & 0 & 0 & 0 & 1 & 6 \\
\hline Feed & 0 & 0 & 0 & 0 & 3 & 0 & 1 & 0 & 0 & 1 & 0 & 5 \\
\hline Bedding & 0 & 0 & 3 & 0 & 11 & 0 & 0 & 1 & 0 & 0 & 0 & 15 \\
\hline
\end{tabular}

${ }^{1}$ For each herd, the information is given for the Staph. aureus pulsotype (PT) that predominated in QMS (PTA), and for other PT found in the herd. Some PT were only found in other animal groups or in "Other samples" as specified in the results section.

${ }^{2}$ One cow in herd V had 2 quarters infected with Staph. aureus PT VA and PT VC, respectively.

${ }^{3}$ One cow in herd II and 3 cows in herd III had both PT A and another PT.

${ }^{4}$ Stanchion bars and cubicle surfaces.

at least one body sample, or at least one sample of the immediate environment of a lactating cow were tested using Fisher's exact test (Statistica 6.0, StatCorp, Inc., Tulsa, OK).

\section{RESULTS}

In total, samples were taken from 191 lactating cows, 48 dry cows, 24 pregnant heifers, 49 young heifers, and 52 heifer calves. Overall, 757 QMS, 1,811 body samples, 902 environmental samples, and 257 other samples were taken. The numbers of samples per herd and animal category are given in Tables 2 to 6 .

\section{Isolation of Staph. aureus}

Overall, 82 (11\%) of the QMS were positive for Staph. aureus $(\mathbf{S a}+)$, and $27 \%$ of the lactating cows were $\mathrm{Sa}+$ in one or more QMS. On average, 1.6 udder quarters per cow were infected, and in $46 \%$ of $\mathrm{Sa}+$ cows the bacteria were found in 2 or more QMS. The proportions of $\mathrm{Sa}+$ cows varied between 9 and $51 \%$ in the 5 herds (Table 2). The proportion of cows Sa+ in QMS was significantly $(P<0.05)$ lower in herds I and IV than in the other herds. Herd III tended $(P=0.055)$ to have a higher proportion of cows $\mathrm{Sa}+$ in QMS than did herd V.

Thirteen percent of all body samples taken from lactating cows were $\mathrm{Sa}+$, and $47 \%$ of the lactating cows were $\mathrm{Sa}+$ in at least one body sample (Table 2). The latter figure varied between 3 and $68 \%$ in the herds. Of all body sites sampled, Staph. aureus was most common on hock skin where $37 \%$ of the samples were Sa+. The corresponding numbers for teat skin, groin, vagina, nares/muzzle, and other skin wounds were $10,7,4,5$, and $35 \%$, respectively. Marked numerical differences in the proportions of Sa+ lactating cows on various body sites were observed between herds (Table 2). Statistical differences between herds were evaluated for hock samples, and a significantly $(P<0.05)$ lower risk of finding Staph. aureus in hock samples was observed in herds IV and V than in the other herds. Herd III tended to have more cows Sa+ in hock samples than herd I ( $P$ $=0.07)$ and herd II $(P=0.052)$.

In the other animal groups Staph. aureus was isolated in at least one body sample from $31 \%$ of dry cows (Table 3), 29\% of heifers in late pregnancy (Table 4), $8 \%$ of young heifers (Table 5), and $29 \%$ of heifer calves 
Table 3. Dry cows: Numbers of animals sampled, numbers of body samples (BS) and environment samples (ES) taken, and numbers (\%) of animals, BS, and ES positive for Staphylococcus aureus (Sa+) divided per pulsotype (PT) in 5 dairy herds (I to V) with Staph. aureus mastitis problems ${ }^{1}$

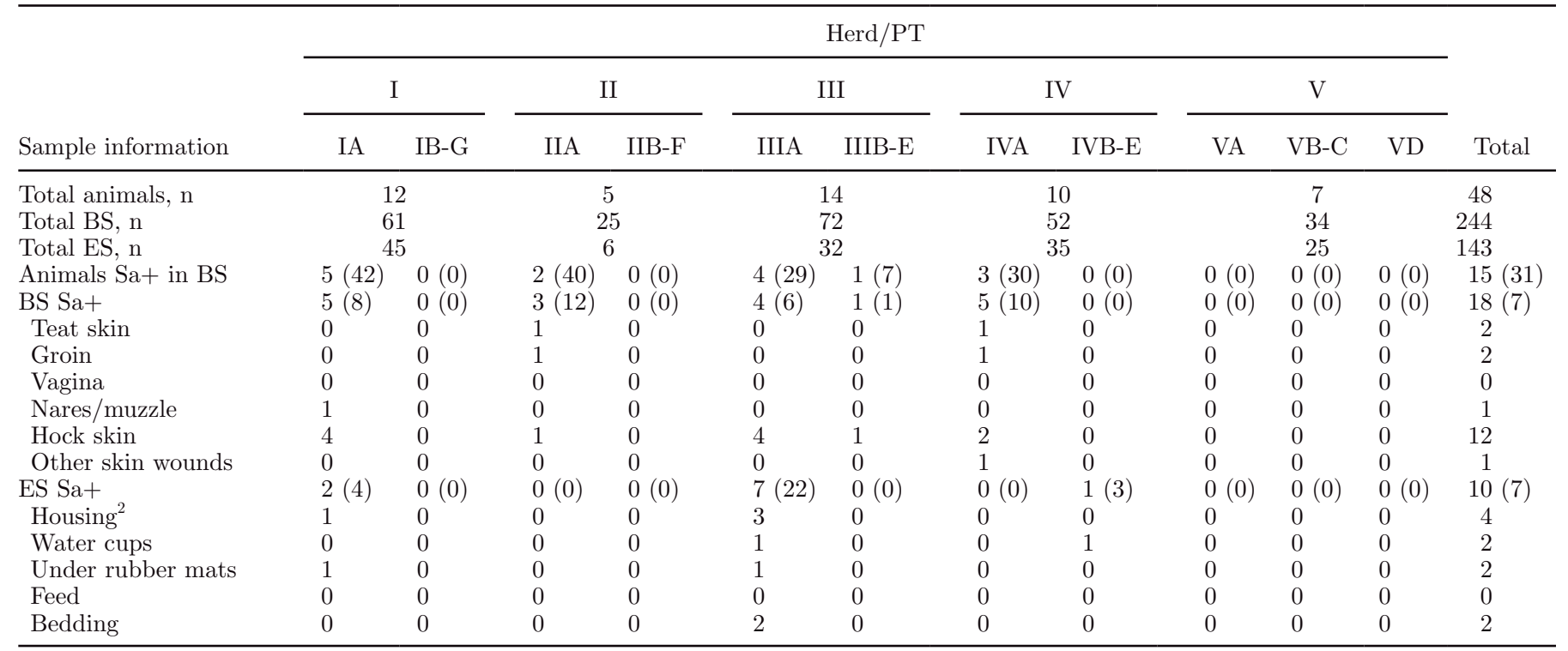

${ }^{1}$ For each herd, the information is given for the Staph. aureus PT that predominated in quarter milk samples of lactating cows (PTA), and for other PT found in the herd. Some PT were only found in other animal groups or in "Other samples" as specified in the results section.

${ }^{2}$ Stanchion bars and cubicle surfaces.

(Table 6). In dry cows and heifers in late pregnancy, the most common Sa+ body site was hock skin. In young heifers a few samples from nares/muzzle and groin were $\mathrm{Sa}+$. In heifer calves, Staph. aureus was most frequently found in other skin wounds, in the umbilical cord area, and in the vagina. Marked variation between herds was found (Tables 3 to 6). In herds IV and V, Staph. aureus was not isolated in body samples from pregnant heifers, young heifers, or heifer calves, and no isolates were found in body samples from dry cows in herd V.

The proportion of $\mathrm{Sa}+$ samples collected in the immediate environment of each animal category varied between 4 and $11 \%$, with the lowest prevalence among young heifers and the highest in lactating cows (Tables $2-6)$. The most common $\mathrm{Sa}+$ site in the immediate environment of lactating cows (Table 2) was housing (stanchion bars and cubicle surfaces), followed by bedding and water cups. In the other animal categories, Staph. aureus was only isolated occasionally from environment samples (Tables 3-6). Variation between herds was observed in all animal groups (Tables 2-6). In herd $\mathrm{V}$, a few $\mathrm{Sa}+$ samples were found in lactating cows, but none in the other animal categories.

In total, Staph. aureus was isolated in $13(5 \%)$ of the other samples. The proportions of $\mathrm{Sa}+$ samples in this sample category were $11,4,4,0$, and $6 \%$, in herds I to $\mathrm{V}$, respectively. Detailed information on these samples is given below.
In herd III, it was more common $(P=0.006)$ to find $\mathrm{Sa}+$ samples in the immediate environment of lactating cows $\mathrm{Sa}+$ in milk than in the immediate environment of lactating cows $\mathrm{Sa}-$ in milk and more common $(P=$ $0.014)$ to find $\mathrm{Sa}+$ samples from the immediate environment of lactating cows $\mathrm{Sa}+$ in body samples than in the immediate environment of lactating cows $\mathrm{Sa}-$ in body samples. Significant associations between finding Staph. aureus in milk, body sites, and environment of lactating cows were not found within the other herds.

\section{PT Identification}

Four to 7 different PT of Staph. aureus were found in each herd, but one predominant PT (the most common, PT A) was found in QMS of each herd (Table 2). All PT were unique for each herd, except for one isolate found in a sample from hock skin in a lactating cow in herd III, which was the same as the predominant PT (IA) in herd I. In herds I, II, and III, the PT predominant in QMS was also frequently found in body samples and environment samples. Including all 5 herds, 93\% of the Staph. aureus isolates from QMS belonged to the predominant PT, whereas 79 and $82 \%$ of the PT found in body samples and samples from the immediate environment of lactating cows, respectively, were of the predominant PT. In herds I, IV, and V, more than one PT was found in QMS (Table 2). Pulsotypes not found 
Table 4. Heifers in late pregnancy: Numbers of animals sampled, numbers of body samples (BS) and environment samples (ES) taken, and numbers (\%) of animals, BS, and ES positive for Staphylococcus aureus (Sa+) divided per pulsotype (PT) in 5 dairy herds (I to V) with Staph. aureus mastitis problems ${ }^{1}$

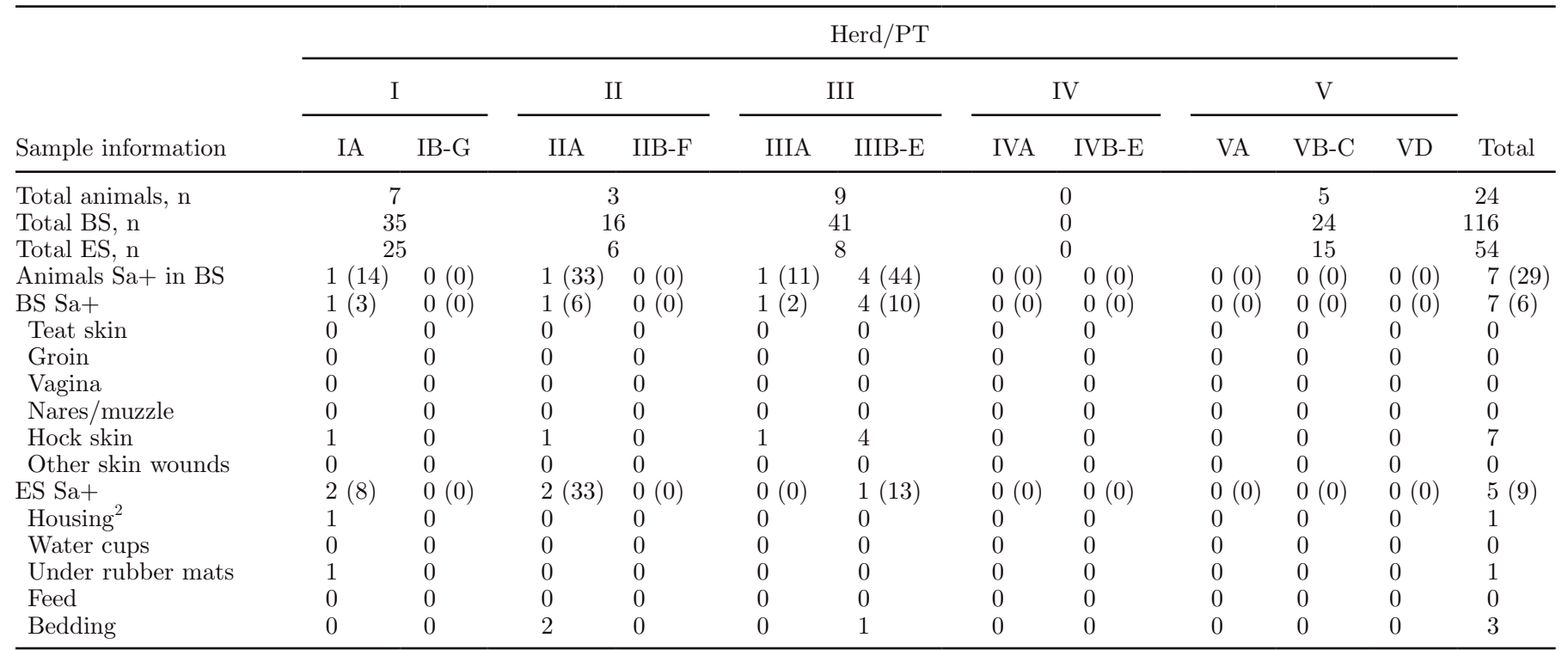

${ }^{1}$ For each herd, the information is given for the Staph. aureus PT that predominated in quarter milk samples of lactating cows (PTA), and for other PT found in the herd. Some PT were only found in other animal groups or in "Other samples" as specified in the results section.

${ }^{2}$ Stanchion bars and cubicle surfaces.

to predominate in milk were rarely found in other types of samples from lactating cows with one exception: PT VD in herd $\mathrm{V}$, which was the most frequently isolated PT in body samples in that herd. In farm IV the predominant PT (IVA) in QMS was not isolated from body sites in lactating cows, but could be demonstrated on body sites of dry cows (Table 3). Most of the Staph. aureus isolates from body sites of other animal groups than lactating cows belonged to the $\mathrm{PT}$ predominant in QMS in each herd (Tables 3-6). In the other animal

Table 5. Young heifers (4-12 mo old): Numbers of animals sampled, numbers of body samples (BS) and environment samples (ES) taken, and numbers (\%) of animals, BS, and ES positive for Staphylococcus aureus (Sa+) divided per pulsotype (PT) in 5 dairy herds (I to V) with Staph. aureus mastitis problems ${ }^{1}$

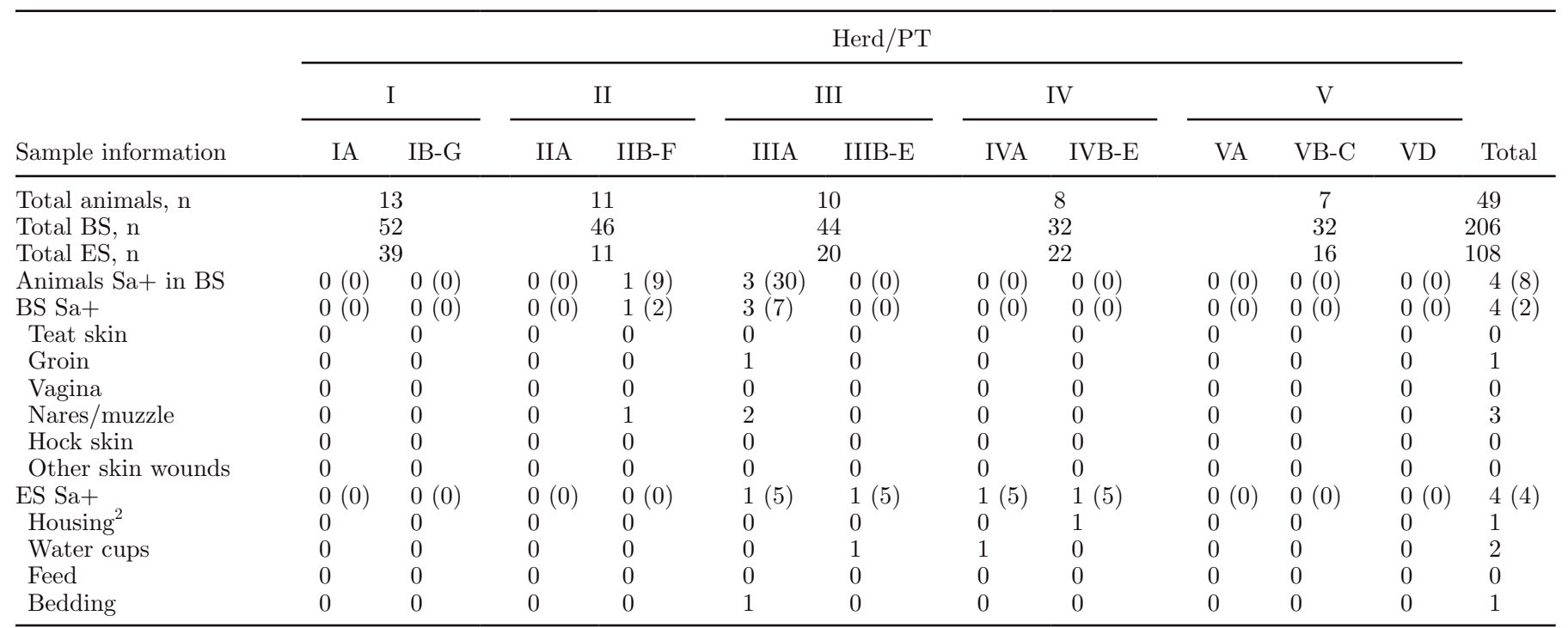

${ }^{1}$ For each herd, the information is given for the Staph. aureus PT that predominated in quarter milk samples of lactating cows (PTA), and for other PT found in the herd. Some PT were only found in other animal groups or in "Other samples" as specified in the results section.

${ }^{2}$ Stanchion bars and cubicle surfaces. 
Table 6. Calves (0-3 mo old): Numbers of animals sampled, numbers of body samples (BS) and environment samples (ES) taken, and numbers (\%) of animals, BS, and ES positive for Staphylococcus aureus (Sa+) divided per pulsotype (PT) in 5 dairy herds (I to V) with Staph. aureus mastitis problems

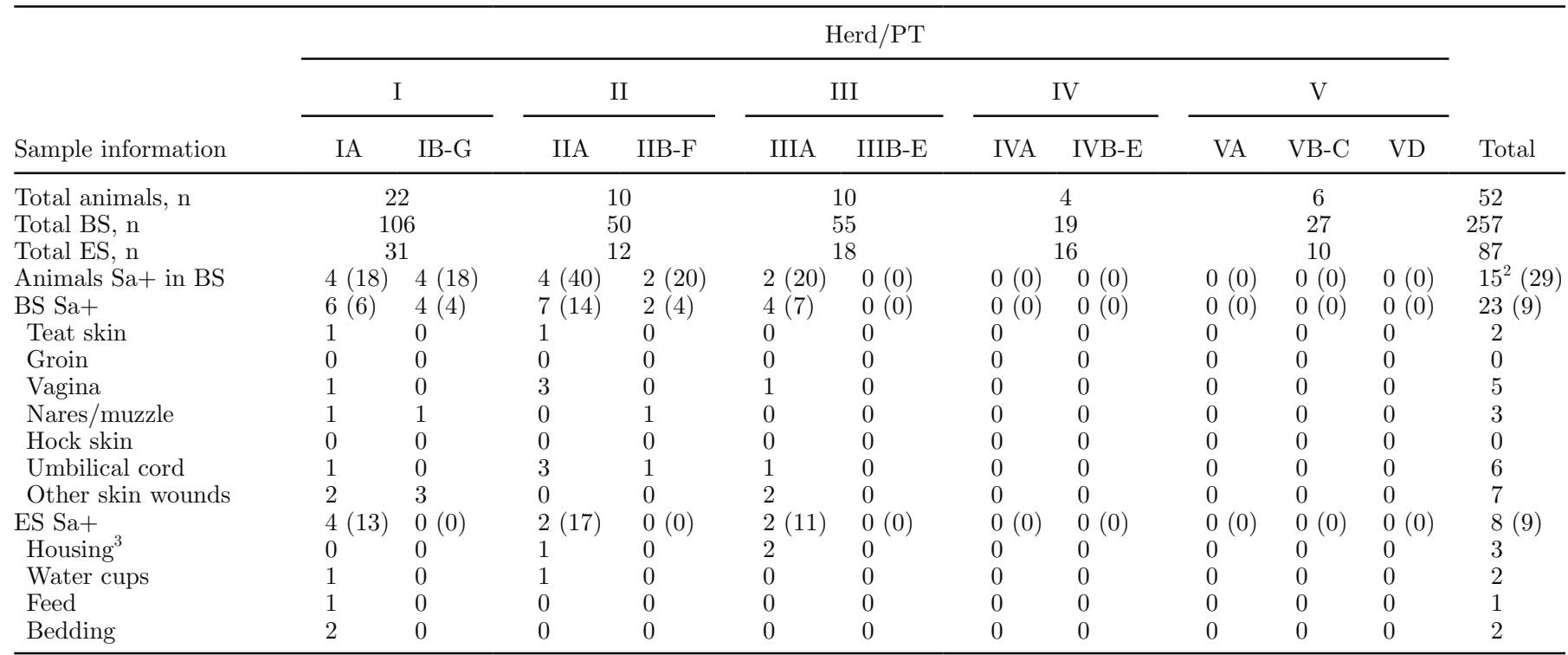

${ }^{1}$ For each herd, the information is given for the Staph. aureus PT that predominated in quarter milk samples of lactating cows (PTA), and for other PT found in the herd. Some PT were only found in other animal groups or in "Other samples" as specified in the results section.

${ }^{2}$ One animal in herd II had both PTA and another PT.

${ }^{3}$ Stanchion bars and cubicle surfaces.

categories there were few isolates from environment samples, but the majority of those (50-100\%) belonged to the PT predominant in QMS (Tables 3-6).

Thirteen other samples were $\mathrm{Sa}+$, originating in the following places (herd and PT are given in parentheses); one human hand with wounds (PT VA), one dog under paws (PT VF), 2 milking strip cups (PT IF and $\mathrm{VA}$ ), one udder cleaning cloth (PT IIIA), 4 buckets for feeding young calves (PT IA, IE, IIA, and IIIA), 2 brushes/hay forks (PT IC and VD), one anti-kicking device (PT IIA), and one fly sample (PT IA).

\section{Hock Condition and Presence of Staph. aureus in Lactating Cows}

Hock lesions were found in $54 \%$ of all lactating cows. Among those lesions, hair loss was found in $62 \%$, and both hair loss and wounds in $38 \%$ of the cases. The herd proportions of cows with hock lesions varied between 42 and $74 \%$. Hock lesions were significantly $(P<$ $0.05)$ more common in herds I and II than in the other herds.

Staph. aureus was found in $37 \%$ of all hock skin samples. Overall, significant associations were found between presence of Staph. aureus in milk and presence of Staph. aureus in hock samples $(P=0.006)$. The risk of finding Staph. aureus was 3.3 times higher in hock samples of cows that also had Staph. aureus in milk than in hock samples of cows without Staph. aureus in milk. The risk of finding Staph. aureus in hock samples was also significantly higher $(\mathrm{OR}=2.7)$ when hock lesions (hair loss or hair loss and wounds) were found on hock skin $(P=0.01)$. There was no significant association between presence of Staph. aureus in milk and presence of hock lesions.

When evaluating within-herd associations between presence of Staph. aureus in milk, presence of Staph. aureus on hock skin, and hock skin condition among lactating cows, a significant association was found only in herd I. In that herd, the risk of finding Staph. aureus in a hock sample was almost 10 times higher $(P=$ 0.016) when the cow had hock lesions compared with when the cow did not have hock lesions.

\section{DISCUSSION}

The results of this study show that Staph. aureus PT found in milk samples were also frequently isolated in body samples and the environment of lactating cows, and sometimes isolated in other animal groups in the herds investigated. Among the other animal groups, it was most common to find Staph. aureus in samples from heifer calves 0 to 3 mo old. Four to 7 Staph. aureus $\mathrm{PT}$ were found within each herd, and they were, with one exception, unique for each herd. In each herd, however, a predominant strain of Staph. aureus was 
found in milk, in concordance with other studies (Joo et al., 2001; Haveri et al., 2008). Pulsotypes other than those found in QMS were sometimes found in body samples and environment samples of lactating cows or of other animal groups. Using the predominant PT as reference within each herd, 1- to 3-band differences were observed between the predominant $\mathrm{PT}$ and some of the other PT within 2 herds (II and V). Thus, those PT can be considered to be probably related to the predominant PT (Tenover et al., 1995). In herd II, PT IIA-C differed by fewer than 3 bands, thus one groin and one umbilical cord sample were closely related to the dominant PT. In herd V, one milk isolate (VC) was closely related to VA. In the 3 remaining herds (I, III, IV), the predominant PT was unique; that is, it differed by $\geq 7$ bands compared with the other PT. Among the less common PT, a cluster of PT more related to each other was found in herd IV where PT IVB (nostrils) and PT IVE (housing) were closely related. To better understand the herd epidemiology of Staph. aureus and the development of PT in herds over time, repeated samplings are necessary and such studies are warranted. The prevalence of Staph. aureus varied markedly between herds and was highest in herds I to III. Because samples were taken only once from each location, during the mid to late housing season, the results only reflect the situation at a single point in time. Moreover, the results do not reveal whether the findings of Staph. aureus in milk were due to intramammary infections or teat canal colonizations.

In herds I to III, Staph. aureus was found on the body, especially on hock skin, of 55 to $68 \%$ of the lactating cows, but the prevalence of cows with Staph. aureus in milk varied between 9 and $51 \%$ in these herds. The majority of isolates from body sites belonged to the PT that predominated in milk. This was also true for isolates from teat skin, which is in agreement with earlier studies (Jorgensen et al., 2005; Haveri et al., 2008; Piccinini et al., 2009). In contrast, Zadoks et al. (2002) found that isolates from teat skin rarely belonged to the same PT as that found in milk, which indicates differences in virulence factors or pathogenesis between Staph. aureus strains. In line with this, the PT (VD) most often isolated from body sites of lactating cows, including teat skin, in herd $\mathrm{V}$ of our study differed from the PT predominant in milk.

Several other studies have focused on finding Staph. aureus in sites related to milking such as milking equipment. This was not the focus of the present study and all samples from such sites were taken between milkings. Therefore, these results are mainly an indication of the efficacy of the cleaning of the equipment. Staphylococcus aureus was not isolated in any teat cup sample, but in herd III the PT predominant in milk was found in one ready-to-use udder cleaning cloth, indicating poor washing of those cloths. In herds I and $\mathrm{V}$, the PT predominant in milk was also found in strip cups, and in herd V, the predominant PT was found on a human hand with wounds. The latter finding is in line with findings of earlier studies (Zadoks et al., 2002; Jorgensen et al., 2005; Haveri et al., 2008). In herds III and V, more than half of the cows with Staph. aureus in milk had 2 quarters infected, which could indicate transmission of infection at milking possibly because of faulty milking equipment or routines. All farmers claimed, however, that the milking system was serviced every year. Automatic detachment of the milking units was only used in herd II, and in herd III milking was performed with 8 milking units, but only one milker. These factors may increase the risk for over-milking. All herds milked high SCC cows and Staph. aureus cows last, and the milking order was updated monthly in most herds according to the interview.

To our knowledge, this study is the first indicating hock skin as an important reservoir for Staph. aureus in herds with Staph. aureus mastitis problems. Even though Staph. aureus was a more common finding on hock skin if hock lesions were present, approximately one quarter of the samples from intact hock skin also contained Staph. aureus. Hock lesions were most common in herds I and II, but herd III had the highest proportion of cows with Staph. aureus positive hock samples. In herd III, it was also common to find Staph. aureus in samples from the immediate environment of cows being Staph. aureus positive in milk or in body samples. Even though a causal relationship cannot be evaluated in this study, we can hypothesize that the hock skin was contaminated from the milk and not the other way around. In the present study, this is indirectly supported by the finding of no association between Staph. aureus in milk and hock lesions even though significant associations were found between Staph. aureus in milk and Staph. aureus on hock skin, and between Staph. aureus on hock skin and hock lesions. Contamination of the bedding by milk leaking from Staph. aureus infected udder quarters could in turn lead to transfer of bacteria from the bedding to the hock skin. It is plausible that milk leakage is more common in high-producing cows. In line with this reasoning, high milk production was found to be significantly associated with presence of Staph. aureus on hock skin when cow data was analyzed (unpublished data). Hock lesions are common in cows housed on rubber mats, in some studies as many as $70 \%$ of cows on rubber mats had lesions (Weary and Taszkun, 2000). All herds in our study used rubber mats and bedded with chopped straw. The type of bedding may also influence the prevalence of hock lesions. Sand and peat litter seem to be bedding materials with 
the lowest risk for hock lesions (Weary and Taszkun, 2000; Andersson, 2007; Fulwider et al., 2007).

In the present study, Staph. aureus was found in groin, vagina, and nares/muzzle in some of the lactating cows, and on stanchion bars, cubicle surfaces, and water cups in some herds. Transmission of bacteria between body sites and environment sites may occur, for example, when the cow is licking or rubbing herself. Among other animal groups, findings of Staph. aureus in body and environment samples were most common in heifer calves of herds I to III, where Staph. aureus was found in samples from skin wounds, umbilical cord, vagina, nares/muzzle, and teat/udder skin as well as in samples from housing, water, feed, and bedding. Most of those isolates were of the PT predominant in milk, but in herd I, other PT were also common in skin wounds. Staphylococcus aureus may have spread from lactating cows to calves via the ventilation or by feeding of milk containing Staph. aureus. In all herds, calves under 6 mo were kept in the same barn as the lactating cows, and milk from cows with high SCC was used to feed calves. In herds I to III, the main PT was also found in samples from buckets used to feed the calves. Staphylococcus aureus could also be spread between calves by inter-sucking. In all herds except in herd V, calves were held in groups from 1 to 4 wk of age, and calf inter-sucking was observed in all herds. Flies have also been suggested as a potential source in transmission of infection, acting as vectors of Staph. aureus (Roberson et al., 1994b; Gillespie et al., 1999). In herd I in the present study, the main Staph. aureus PT was isolated from flies collected in the barn of lactating cows and calves, which indicates that this was another possible route of transmission and emphasizes the importance of fly control.

The lowest prevalence of Staph. aureus on body sites was found in young heifers 4 to 12 mo old, which may reflect the fact that contact between this group and the lactating cows was limited. This result is in line with findings by Roberson et al. (1994a), but not with those of Matos et al. (1991), who found Staph. aureus in body samples in that age group more frequently than in 0 - to 3 -mo-old calves.

It has been suggested that preparturient heifers are a potential source of Staph. aureus (Roberson et al., 1994a). In our study, 7 out of 24 heifers in late pregnancy were Staph. aureus positive on body sites, but in 4 of those heifers, a PT other than the one predominant in milk was found. Thus, late pregnant heifers did not appear to be an important source of infection in these herds. Samples from udder secretions were not, however, taken from this animal category.

Marked interherd variation in the proportion of cows with Staph. aureus in milk, body, or environment samples was found. The reasons for this are not known, but differences in virulence factors between Staph. aureus strains may be of importance as well as differences in management routines. Although difficult to separate from other herd effects, some facts in the present study indicate that the Staph. aureus PT differed in virulence. The mean milk yield per cow was highest in the herd with the highest prevalence of Staph. aureus in milk (herd III), followed by the herd with the second highest prevalence (herd II). These 2 herds also had the lowest proportion of cows with a persistently high SCC $(>300,000$ cells $/ \mathrm{mL})$. Herd III also had the lowest proportion of veterinarian-treated cases of clinical mastitis. Intramammary infection of some Staph. aureus strains can result in significantly lower SCC than other strains, which might be an indication that these strains cause a lower inflammatory response and thereby have a better chance to spread in the herd (Zecconi et al., 2005; Dingwell et al., 2006). A lower ability to be internalized could be one explanation why some strains of Staph. aureus cause a less pronounced increase in SCC. One mechanism that could explain the degree of binding and internalization of Staph. aureus is the difference between Staph. aureus strains with regard to the presence or absence of fibronectin-binding proteins (Brouillette et al., 2003). The possibility that some strains of Staph. aureus might be less contagious and more prone to spread via the environment has been discussed and demonstrated elsewhere (Larsen et al., 2000; Sommerhauser et al., 2003; Fournier et al., 2008). In our study there was one PT (VD) in herd V that was frequently isolated from body sites of lactating cows but was only isolated from milk of one cow and in one environment sample in the herd, suggesting that it was a low pathogenic strain. As mentioned earlier, management factors may also influence the prevalence of Staph. aureus on body sites and in the environment, and some differences in milking-related management were found between the herds (data not shown).

Staphylococcus aureus mastitis control programs have had limited success in some herds. The results from the present study indicate that such programs should be adjusted depending on the nature of the Staph. aureus strains found in the herd. One should be aware that almost any living organism or item in the barn can act as a reservoir or fomite of Staph. aureus and participate in the transmission of bacteria. However, the most important sources of Staph. aureus involved in mastitis are to be found in the udder and the body of lactating cows and in their immediate environment. Sampling milk, hock skin, and the immediate environment of lactating cows and comparing PT would give a good estimate of the characteristics of the Staph. aureus strains present and provide important knowledge on how to stop the 
spread of Staph. aureus within the herd. The results also emphasize the importance of grouping Staph. aureus-infected cows separately. All types of skin wounds, especially hock lesions, should be avoided as they are likely reservoirs of infection in all age groups. Good hygienic conditions in the cubicles are also important, and cubicles should be cleaned thoroughly when animals are moved to a new place in the tie-stall barn; for example, when changing milking order.

In future studies of this type, repeated samplings should be performed to investigate whether seasonal differences occur. Moreover, clinical cases should be included and the presence and persistency of intramammary infections should be evaluated. In the present study, milk samples $(n=7)$ from clinical cases of mastitis could only be collected in herd I (data not shown), and Staph. aureus PT found in all those cases were of the PT predominant in milk in that herd.

\section{CONCLUSIONS}

The results from PFGE typing of Staph. aureus showed that isolates with genotypes indistinguishable from those found in milk also dominated in extramammary sites within the dairy herds studied, and hock skin was identified as an important reservoir of Staph. aureus. The results contribute new knowledge necessary to improve strategies for udder health control in the herds.

\section{ACKNOWLEDGMENTS}

This study was financially supported by the Swedish Research Council for Environment, Agricultural Sciences and Spatial Planning (Formas, Stockholm, Sweden). The assistance of Anna Eriksson, Marih Jonsson, Ann Nyman, and Maria Persson of the National Veterinary Institute (Uppsala, Sweden) is gratefully acknowledged.

\section{REFERENCES}

Andersson, K. 2007. Peat litter to Swedish dairy cows [In Swedish]. Swedish University of Agricultural Science, Uppsala.

Bannerman, T. L., G. A. Hancock, F. C. Tenover, and J. M. Miller 1995. Pulsed-field gel electrophoresis as a replacement for bacteriophage typing of Staphylococcus aureus. J. Clin. Microbiol. 33:551-555.

Brouillette, E., G. Grondin, L. Shkreta, P. Lacasse, and B. G. Talbot. 2003. In vivo and in vitro demonstration that Staphylococcus aureus is an intracellular pathogen in the presence or absence of fibronectin-binding proteins. Microb. Pathog. 35:159-168.

Davidson, I. 1961. The epidemiology of staphylococcal mastitis. Vet. Rec. 73:1015-1018

Devriese, L. A. 1981. Baird-Parker medium supplemented with acriflavine, polymyxins and sulphonamide for the selective isolation of Staphylococcus aureus from heavily contaminated materials. J. Appl. Bacteriol. 50:351-357.
Dingwell, R. T., K. E. Leslie, P. Sabour, D. Lepp, and J. Pacan. 2006 Influence of the genotype of Staphylococcus aureus, determined by pulsed-field gel electrophoresis, on dry-period elimination of subclinical mastitis in Canadian dairy herds. Can. J. Vet. Res. 70:115-120.

Ericsson Unnerstad, H., A. Lindberg, K. Persson Waller, T. Ekman, K. Artursson, M. Nilsson Öst, and B. Bengtsson. 2009. Microbial aetiology of acute clinical mastitis and agent-specific risk factors. Vet. Microbiol. 137:90-97.

Ferguson, J. D., G. Azzaro, M. Gambina, and G. Licitra. 2007 Prevalence of mastitis pathogens in Ragusa, Sicily, from 2000 to 2006. J. Dairy Sci. 90:5798-5813.

Fournier, C., P. Kuhnert, J. Frey, R. Miserez, M. Kirchhofer, T. Kaufmann, A. Steiner, and H. U. Graber. 2008. Bovine Staphylococcus aureus: Association of virulence genes, genotypes and clinical outcome. Res. Vet. Sci. 85:439-448.

Fox, L. K., C. T. Gaskins, D. D. Hancock, D. Newkirk, and C. T Hutton. 1992. Comparison of media to isolate Staphylococcus aureus from teat skin and milking unit liners. Cornell Vet. 82:225-231.

Fox, L. K. M. Gershman, D. D. Hancock, and C. T. Hutton. 1991. Fomites and reservoirs of Staphylococcus aureus causing intramammary infections as determined by phage typing: The effect of milking time hygiene practices. Cornell Vet. 81:183193.

Fulwider, W. K., T. Grandin, D. J. Garrick, T. E. Engle, W. D. Lamm, N. L. Dalsted, and B. E. Rollin. 2007. Influence of free-stall base on tarsal joint lesions and hygiene in dairy cows. J. Dairy Sci. 90:3559-3566.

Gianneechini, R., C. Concha, R. Rivero, I. Delucci, and J. Moreno Lopez. 2002. Occurrence of clinical and sub-clinical mastitis in dairy herds in the West Littoral Region in Uruguay. Acta Vet. Scand. 43:221-230.

Gillespie, B. E., W. E. Owens, S. C. Nickerson, and S. P. Oliver. 1999 Deoxyribonucleic acid fingerprinting of Staphylococcus aureus from heifer mammary secretions and from horn flies. J. Dairy Sci. 82:1581-1585.

Haveri, M., M. Hovinen, A. Roslof, and S. Pyörälä. 2008. Molecular types and genetic profiles of Staphylococcus aureus strains isolated from bovine intramammary infections and extramammary sites. J. Clin. Microbiol. 46:3728-3735.

Hogan, J., R. N. González, R. Harmon, S. C. Nickerson, S. J. Oliver, J. Pankey, and K. Smith. 1999. Staphylococci. Pages $65-77$ in Laboratory Handbook on Bovine Mastitis. National Mastitis Council, Madison, WI

Joo, Y. S., L. K. Fox, W. C. Davis, G. A. Bohach, and Y. H. Park. 2001. Staphylococcus aureus associated with mammary glands of cows: Genotyping to distinguish different strains among herds. Vet. Microbiol. 80:131-138.

Jorgensen, H. J., T. Mork, D. A. Caugant, A. Kearns, and L. M. Rorvik. 2005. Genetic variation among Staphylococcus aureus strains from Norwegian bulk milk. Appl. Environ. Microbiol $71: 8352-8361$

Larsen, H. D., K. H. Sloth, C. Elsberg, C. Enevoldsen, L. H. Pedersen, N. H. Eriksen, F. M. Aarestrup, and N. E. Jensen. 2000. The dynamics of Staphylococcus aureus intramammary infection in nine Danish dairy herds. Vet. Microbiol. 71:89-101.

Matos, J. S., D. G. White, R. J. Harmon, and B. E. Langlois. 1991. Isolation of Staphylococcus aureus from sites other than the lactating mammary gland. J. Dairy Sci. 74:1544-1549.

Middleton, J. R., L. K. Fox, J. M. Gay, J. W. Tyler, and T. E. Besser. 2002. Use of pulsed-field gel electrophoresis for detecting differences in Staphylococcus aureus strain populations between dairy herds with different cattle importation practices. Epidemiol. Infect. 129:387-395.

Olde Riekerink, R. G., H. W. Barkema, D. F. Kelton, and D. T. Scholl. 2008. Incidence rate of clinical mastitis on Canadian dairy farms. J. Dairy Sci. 91:1366-1377.

Piccinini, R., L. Cesaris, V. Dapra, V. Borromeo, C. Picozzi, C. Secchi, and A. Zecconi. 2009. The role of teat skin contamination in the epidemiology of Staphylococcus aureus intramammary infections. J. Dairy Res. 76:36-41. 
Pitkala, A., M. Haveri, S. Pyorala, V. Myllys, and T. HonkanenBuzalski. 2004. Bovine mastitis in Finland 2001-Prevalence, distribution of bacteria, and antimicrobial resistance. J. Dairy Sci. 87:2433-2441.

Quinn, P. J., M. E. Carter, B. Markey, and G. R. Carter. 1994. Staphylococcus species. Pages 118-126 in Mosby's Clinical Veterinary Microbiology. Wolfe, London, UK.

Roberson, J. R., L. K. Fox, D. D. Hancock, and T. E. Besser. 1992. Evaluation of methods for differentiation of coagulase-positive staphylococci. J. Clin. Microbiol. 30:3217-3219.

Roberson, J. R., L. K. Fox, D. D. Hancock, C. C. Gay, and T. E. Besser. 1994a. Coagulase-positive Staphylococcus intramammary infections in primiparous dairy cows. J. Dairy Sci. 77:958-969.

Roberson, J. R., L. K. Fox, D. D. Hancock, J. M. Gay, and T. E. Besser. 1994b. Ecology of Staphylococcus aureus isolated from various sites on dairy farms. J. Dairy Sci. 77:3354-3364.

Roberson, J. R., L. K. Fox, D. D. Hancock, J. M. Gay, and T. E. Besser. 1998. Sources of intramammary infections from Staphylococcus aureus in dairy heifers at first parturition. J. Dairy Sci. 81:687693.

Sommerhauser, J., B. Kloppert, W. Wolter, M. Zschock, A. Sobiraj, and K. Failing. 2003. The epidemiology of Staphylococcus aureus infections from subclinical mastitis in dairy cows during a control programme. Vet. Microbiol. 96:91-102.
Spencer, G. R., and J. Lasmanis. 1952. Reservors of infection of Micrococcus pyogenes in bovine mastitis. Am. J. Vet. Res. 13:500503.

Tenover, F. C., R. D. Arbeit, R. V. Goering, P. A. Mickelsen, B. E. Murray, D. H. Persing, and B. Swaminathan. 1995. Interpreting chromosomal DNA restriction patterns produced by pulse-field gel electrophoresis: Criteria for bacterial strain typing. J. Clin. Microbiol. 33:2233-2239.

Weary, D. M., and I. Taszkun. 2000. Hock lesions and free-stall design. J. Dairy Sci. 83:697-702.

Zadoks, R. N., W. B. van Leeuwen, D. Kreft, L. K. Fox, H. W. Barkema, Y. H. Schukken, and A. van Belkum. 2002. Comparison of Staphylococcus aureus isolates from bovine and human skin, milking equipment, and bovine milk by phage typing, pulsedfield gel electrophoresis, and binary typing. J. Clin. Microbiol. 40:3894-3902.

Zecconi, A., E. Binda, V. Borromeo, and R. Piccinini. 2005. Relationship between some Staphylococcus aureus pathogenic factors and growth rates and somatic cell counts. J. Dairy Res. 72:203-208.

Zecconi, A., L. A. Calvinho, and L. K. Fox. 2006. Staphylococcus aureus intramammary infections. Bull. IDF 408:1-42. 